\title{
PERAN KECINTAAN MEREK DALAM MEMBANGUN HUBUNGAN DENGAN PELANGGAN (Studi pada Pengguna iPhone di Denpasar)
}

\author{
I Dewa Gede Kresna Wirawan ${ }^{1}$ \\ Putu Gde Sukaatmadja ${ }^{2}$
}

\author{
${ }^{1}$ Fakultas Ekonomi dan Bisnis Universitas udayana (Unud), Bali - Indonesia \\ e-mail: krsena.wirawan45@gmail.com \\ ${ }^{2}$ Fakultas Ekonomi dan Bisnis Universitas udayana (Unud), Bali - Indonesia
}

\begin{abstract}
ABSTRAK
Penelitian ini bertujuan menguji peran kecintaan merek dengan pendekatan kausal (identifikasi merek, kepercayaan merek dan komitmen merek) yang berdampak pada wordof-mouth dan kesediaan untuk membayar dengan harga premium pada pengguna iPhone. Penelitian menggunakan metode $P L S$, sampel sebanyak 100 orang yang berdomisili di Denpasar. Penentuan sampel dengan metode nonprobability sampling, yaitu purposive sampling, dengan kriteria responden yang menggunakan iPhone 2 tahun terakhir. Penelitian ini menemukan identifikasi merek berpengaruh positif dan signifikan terhadap kecintaan merek dan komitmen merek. Kepercayaan merek berpengaruh positif dan signifikan terhadap kecintaan merek dan komitmen merek. Kecintaan merek berpengaruh positif dan signifikan terhadap komitmen merek, word-of-mouth, dan kesediaan membayar dengan harga premium. Komitmen merek berpengaruh positif dan signifikan terhadap word-ofmouth terhadap kesediaan membayar dengan harga premium. Implikasinya, meningkatkan kesadaran merek iPhone sehingga pengguna dapat dengan mudah mengenali merek melalui bentuk produk, durabilitas produk, dan kecanggihannya. Ini akan berdampak pada penilaian positif terhadap iPhone dan meningkatkan emosional pengguna iPhone.
\end{abstract}

Kata Kunci: hubungan-merek pelanggan, kecintaan merek, word-of-mouth, kesediaan membayar dengan harga premium

\begin{abstract}
Study aims to examine the role of brand love with a causal approach (identification, trust and commitment). The study used the PLS method, a sample of 100 people are domiciled in Denpasar. Determination of sample with nonprobability sampling method, that is purposive sampling, with criterion of responden using iPhone 2 last year. This study found identification has a positive and significant impact on brand love and commitment. Trust has a positive and significant impact on brand love and commitment. Brand love has a positive and significant impact on commitment, word-of-mouth, willingness to pay a premium price. Commitment has a positive and significant effect on word-of-mouth on willingness to pay a premium price. The implication is to increase the awareness of the iPhone so that users can easily recognize the brand through product form, durability, and sophistication. The impact on the positive assessment of the iPhone and emotional increase iPhone users.
\end{abstract}

Keywords: consumer brand-relationships, brand love, word-of-mouth, willingness to pay a price premium 


\section{PENDAHULUAN}

Dewasa ini, banyak konsumen yang tertarik dan berpindah menggunakan telepon jenis smartphone. Berbagai merek smartphone semakin banyak beredar di Indonesia, salah satunya adalah merek Apple. Produk-produk Apple sendiri, khususnya iPhone, tentu sudah tidak asing lagi di kalangan masyarakat dunia, termasuk di Indonesia. Smartphone iPhone sebagai produk andalan, berhasil menjadi penguasa pasar smartphone dunia setelah mengalahkan penjualan Samsung pada triwulan IV 2016. Data IDC yang dirilis 1 Februari 2017 menunjukkan bahwa pengiriman iPhone ke seluruh penjuru dunia pada triwulan IV 2016 mencapai 78,3 juta unit naik 4,7 persen dari periode yang sama 2015. Jika dibandingkan dengan triwulan sebelumnya, penjualan iPhone melonjak 72 persen. Walaupun angka penjualan iPhone secara global di akhir tahun 2016 lebih tinggi dari pesaingnya Samsung, merek smartphone yang menjadi pilihan masyarakat Indonesia masih tetap Samsung.

Hal ini dapat diperoleh dari riset yang dilakukan Total Brand Index Indonesia tahun 2016 dimana sebanyak 43,4 \% masyarakat Indonesia menyatakan merek smartphone pilihannya adalah Samsung dan masyarakat Indonesia yang memilih smartphone iPhone hanya sebanyak 5,8\%. Namun hal ini berbeda ketika berbicara tentang merek secara keseluruhan, bukan hanya merek smartphone. Berdasarkan data Interbrand, 2015 dan 2016, merek Apple memiliki nilai yang lebih tinggi dibandingkan merek kompetitornya Samsung yaitu dengan pertumbuhan nilai sebesar 5\%. 
I Dewa Gede Kresna Wurawan, Putu Gde Sukaatmadja. Peran Kecintaan Merek...

Meskipun rata-rata penjualan merek smartphone iPhone berada dibawah Samsung dan pangsa pasarnya mulai direbut oleh smartphone buatan China pengguna smartphone iPhone tetap setia menggunakan produk merek Apple. Untuk mempertajam isu-isu atau fenomena mengenai hal ini, maka dilakukan prariset pada pengguna smartphone iPhone di Kota Denpasar yang dilakukan pada bulan Juli sampai Agustus 2017. Sampel dalam pra-riset ditentukan menggunakan pendekatan normal yaitu rentang 20 sampai 30 responden (Sekaran, 2011: 23), maka pra-riset menggunakan 25 responden. Berdasarkan hasil wawancara, beberapa diantaranya menyatakan bahwa smartphone iPhone merupakan produk yang sangat mahal. Selain itu, mereka menggunakan smartphone iPhone untuk memenuhi kebutuhannya atau hanya sekedar sebagai trend dan gaya hidup saja. Namun, mayoritas responden merasa puas selama menggunakan smartphone iPhone karena produk ini memberikan banyak kemudahan-kemudahan dan fiturfitur unggulan dalam operasionalnya. Sebanyak 89 persen responden menyatakan bahwa mereka bersedia membeli produk ini dengan harga mahal dan 48 persen responden menyatakan bahwa mereka telah merekomendasikan smartphone iPhone kepada orang lain. Berdasarkan penjelasan hasil pra-riset, keberhasilan dari smartphone iPhone tidak lepas dari konsumen yang puas terhadap produk yang ditawarkan. Konsumen yang puas akan menjadi loyal kepada suatu merek atau perusahaan.

Merek dapat tercermin dalam cara konsumen berpikir, merasa, dan bertindak dalam hubungannya dengan merek, dan juga harga, pangsa pasar, dan profitabilitas yang diberikan merek bagi perusahaan. Hubungan merek konsumen 
I Dewa Gede Kresna Wurawan, Putu Gde Sukaatmadja. Peran Kecintaan Merek...

telah menguji berbagai konsep relasional, termasuk kepercayaan merek, komitmen merek dan identifikasi mereka (Albert and Merunka, 2013). Tiga model ini akan berperan dalam rasa kesetiaan dan ekspresi terhadap objek bagi para peneliti yang telah melakukan penelitian terhadap konsep cinta terhadap merek (Ismail et al., 2012).

\section{KAJIAN PUSTAKA}

Aaker (2015:218), menyatakan bahwa identifikasi merek adalah seperangkat unik asosiasi merek yang memenuhi jaringan atau mempertahankan strategi pemasaran merek. Sallam (2014), mendefinisikan identifikasi merek adalah sejauh mana konsumen melihat citra dirinya sendiri sebagai tolak ukur dalam melihat suatu merek. Identifikasi merek memiliki pengaruh yang positif terhadap kecintaan merek.

Kecintaan merek adalah pengalaman emosional yang sangat kuat baik dari segi hubungan interpersonal dan hubungan antar konsumen dan merek Hwang and Kandampully (2012). Albert and Marunka (2013:258), mendefinisikan kecintaan merek sebagai tingkatan ikatan emosional dan keinginan yang dimiliki seseorang terhadap merek yaitu sikap yang dimiliki oleh seseorang terhadap merek tertentu, yang melibatkan kecenderungan untuk berpikir, merasakan, dan berperilaku dengan cara tertentu terhadap merek tersebut.

Komitmen merek merupakan keadaan psikologis yang menunjukkan sikap positif konsumen terhadap nama komersial dan keinginan untuk memiliki hubungan dengan produk atau layanan (Walsh et al., 2010). Sedangkan Tavalaee dan Baqeri (2013), berpendapat bahwa komitmen sebagai penghubung orang 
I Dewa Gede Kresna Wurawan, Putu Gde Sukaatmadja. Peran Kecintaan Merek...

dengan faktor dan tindakan pribadi, ketika komitmen itu nyata, berarti orang bertanggung jawab atas perilaku dan tindakan mereka.

Kotler and Keller (2012: 190) menyatakan bahwa komunikasi dari mulut ke mulut merupakan proses komunikasi yang berupa pemberian rekomendasi, baik secara individu maupun kelompok terhadap suatu produk atau jasa yang bertujuan untuk memberikan informasi secara personal. Sedangkan menurut Tjiptono (2012: 164), word-of-mouth merupakan pernyataan (secara personal dan nonpersonal) yang disampaikan oleh orang lain selain penyedia layanan kepada pelanggan yang bersifat kredibel dan efektif karena disampaikan oleh orang-orang yang dipercayai konsumen.

Netemeyer et al. (2004), mendefinisikan kesediaan membayar harga premium sebagai besarnya jumlah yang konsumen bersedia bayarkan untuk membeli sebuah merek yang mereka sukai dibandingkan merek yang sejenis atau lebih kecil. Kotler dan Keller (2012: 56) juga mengungkapkan penyebab konsumen bersedia membayar harga yang lebih tinggi untuk produk perusahaan karena keunggulan yang dirasakan dari suatu produk atau jasa mengesankan kualitas unggul. Berikut tersaji kerangka konseptual penelitian pada Gambar 1.

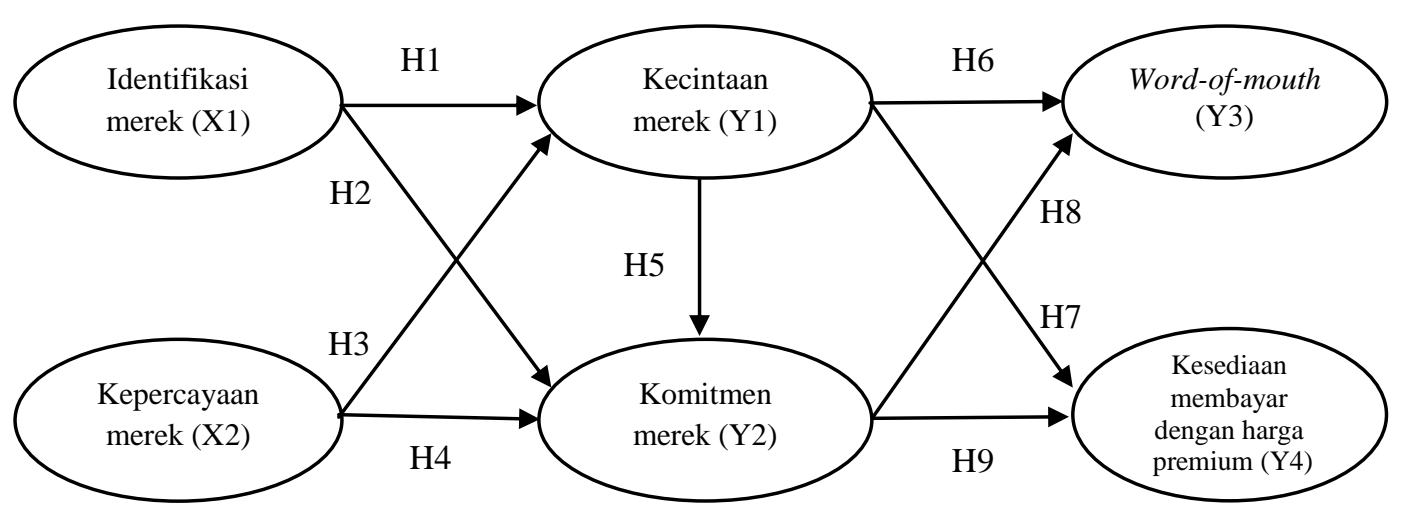

Gambar 1. Model Konseptual Penelitian 
Identifikasi merek menurut Sallam (2014) adalah sejauh mana konsumen melihat citra dirinya sendiri sebagai tolak ukur dalam melihat suatu merek. Konsumen yang mempunyai identifikasi merek yang kuat akan menjadi lebih loyal kepada merek tersebut untuk mendukung tujuan perusahaan, mempertahankan reputasi, mendukung produk perusahaan dan loyal (Bhattacharya et al., 2011). Identifikasi merek memiliki pengaruh positif terhadap kecintaan merek. Beberapa temuan menunjukkan adanya hubungan positif identifikasi merek dengan kecintaan merek (Albert and Merunka 2013; Motahari et al., 2014)

$\mathrm{H}_{1}$ : Identifikasi merek berpengaruh positif signifikan terhadap kecintaan merek

Identifikasi merek juga memiliki pengaruh positif terhadap komitmen merek. Hasil penelitian Albert and Merunka (2013) dan Kazemi et al. (2013), menunjukkan identifikasi merek berpengaruh positif terhadap komitmen merek. Bachman and Wilkins (2014), yang menyelidiki identifikasi merek dan komitmen merek pelanggan sebagai kesetiaan dan niat membeli, hasil penelitian menunjukkan identifikasi merek pelanggan berpengaruh terhadap komitmen afektif.

$\mathrm{H}_{2}$ : Identifikasi merek berpengaruh positif signifikan terhadap komitmen merek

Murthy dalam Kertajaya (2009:11), dari sudut pandang perusahaan, kepercayaan merek adalah merek yang berhasil menciptakan brand experience yang berkesan dalam diri konsumen yang berkelanjutan dalam jangka panjang, berdasarkan integritas, kejujuran dan kesantunan merek tersebut. Hasil penelitian Susanti (2015), menyatakan bahwa kepercayaan merek berpengaruh signifikan 
I Dewa Gede Kresna Wurawan, Putu Gde Sukaatmadja. Peran Kecintaan Merek...

terhadap kecintaan merek pada pengguna sepatu Adidas di Surabaya, begitu juga dengan penelitian Albert and Merunka (2013), yang menunjukkan bahwa kepercayaan merek berpengaruh positif dan signifikan terhadap kecintaan merek.

$\mathrm{H}_{3}$ : Kepercayaan merek berpengaruh positif dan signifikan terhadap kecintaan merek

Kepercayaan merek memiliki pengaruh positif terhadap komitmen merek. Hasil dalam penelitian dari Louis and Lombart (2010), yang menjelaskan bahwa kepercayaan merek berpengaruh positif signifikan terhadap komitmen merek. Li et al. (2014), mengkonfirmasi bahwa komitmen terhadap merek apapun merupakan tingkat risiko bagi konsumen individual, oleh karena itu, konsumen harus mengembangkan kepercayaan merek sebelum merasakan dan menampilkan komitmen. Susanti (2015), mengatakan bahwa kepercayaan merek berpengaruh signifikan terhadap komitmen merek pada pengguna sepatu Adidas di Surabaya. $\mathrm{H}_{4}$ : Kepercayaan merek berpengaruh positif signifikan terhadap komitmen merek Studi oleh Maisam and Mahsa (2016), kecintaan merek dan komitmen merek memiliki dampak positif yang signifikan terhadap kata positif dari mulut ke mulut, sejalan dengan penelitian Albert and Merunka (2013) menjelaskan bahwa kecintaan merek dan komitmen merek keduanya mewakili variabel kepercayaan dan identifikasi dan konsekuensi (kecintaan merek, komitmen merek, kesediaan membayar membayar dengan harga premium dan word-ofmouth).

$\mathrm{H}_{5}$ : Kecintaan merek berpengaruh positif signifikan terhadap komitmen merek 
I Dewa Gede Kresna Wurawan, Putu Gde Sukaatmadja. Peran Kecintaan Merek...

Hubungan lain yang telah diidentifikasi dalam studi yang dilakukan Albert and Merunka (2013) adalah word-of-mouth. Sumardy et al. (2011:63) word-of-mouth sebagai kegiatan pemasaran yang dilakukan oleh sebuah merek agar konsumen membicarakan, mempromosikan, dan mau menjual merek kepada orang lain. Beberapa penelitian telah menemukan bahwa kecintaan merek memiliki pengaruh yang signifikan terhadap word-of-mouth (Ismail et al., 2012; Albert and Merunka, 2013; Ahdah, 2014).

$\mathrm{H}_{6}$ : Kecintaan merek berpengaruh positif signifikan terhadap word-of-mouth

Komitmen merek juga ditemukan memiliki pengaruh yang positif terhadap word-of mouth. Hasil penelitian Albert and Merunka (2013); Tuskej et al. (2013), Maisam and Mahsa (2016), kecintaan merek dan komitmen merek memiliki dampak positif yang signifikan terhadap kata positif dari mulut ke mulut.

$\mathrm{H}_{7:}$ Komitmen merek berpengaruh positif signifikan terhadap word-of-mouth

Rodrigues and Reis (2013), dalam penelitiannya menunjukkan bahwa untuk konsumen Portugis, merek Zara dianggap sebagai merek pilihan dan karena konsumen tersebut setia dan bersedia membayar harga yang lebih tinggi dibandingkan dengan yang dilakukan oleh merek Modalfa. Albert and Merunka (2013) dan Cantista (2015) menunjukkan kecintaan merek berpengaruh positif yang signifikan terhadap kesediaan membayar dengan harga premium.

$\mathrm{H}_{8}$ : Kecintaan merek berpengaruh positif signifikan terhadap kesediaan membayar dengan harga premium 
Beberapa studi juga menemukan komitmen merek memiliki hubungan yang positif dengan kesediaan membayar dengan harga premium (Chaudhuri and Holbrook, 2002; Albert and Merunka, 2013).

$\mathrm{H}_{9}$ : Komitmen merek berpengaruh positif signifikan terhadap kesediaan membayar dengan harga premium.

\section{METODE PENELITIAN}

Penelitian ini menggunakan data kuantitatif yang merupakan data skor total masing - masing variabel. Selanjutnya, data kualitatif berupa gambaran umum perusahaan dan hasil riset awal yang dilakukan melalui wawancara kepada pengguna iPhone. Data yang digunakan dalam penelitian ini bersumber dari sumber primer yang diperoleh dari pengguna iPhone di Denpasar yang menjadi repsonden dan sumber sekunder diperoleh dari artikel online dan artikel penelitian terkait topik identifikasi merek, kepercayaan merek, kecintaan merek, komitmen merek, word-of-mouth, dan kesediaan membayar harga premium.

Lokasi penelitian dilakukan di Kota Denpasar. Populasi dalam penelitian ini adalah seluruh pengguna iPhone aktif yang berdomisili di Denpasar. Sampel ditentukan dengan metode nonprobability sampling, yaitu purposive sampling, dengan kriteria pengguna yang sedang menggunakan iPhone minimal selama 2 tahun terakhir. Sampel yang digunakan adalah sebanyak 100 orang. Hal ini telah sesuai dengan kriteria rentang ukuran sampel yang direkomendasikan untuk PLS yaitu berkisar antara 30 sampai 100 (Ghozali, 2011:5).

Instrumen penelitian menggunakan kuesioner yang diberikan kepada pengguna iPhone di Denpasar. Skala pengukuran yang digunakan adalah Skala 
I Dewa Gede Kresna Wurawan, Putu Gde Sukaatmadja. Peran Kecintaan Merek...

Likert 1 (Sangat Tidak Setuju) sampai 5 (Sangat Setuju). Data dikumpulkan dengan mengirimkan kuesioner yang diberikan secara pribadi. Setelah kuesioner dikembalikan, data ditabulasi dan selanjutnya dianalisis dengan Partial Least Square (PLS), digunakan untuk menguji hubungan antar variabel yang digunakan dalam hipotesis.

\section{HASIL DAN PEMBAHASAN}

Berdasarkan hasil survei, responden didominasi oleh laki - laki sebanyak 73 persen, sedangkan sisanya perempuan sebesar 27 persen. Berdasarkan usia, mayoritas responden berusia 18 sampai 27 tahun yaitu sebesar 7 persen, kemudian diikuti oleh responden berusia 28 sampai 37 tahun yaitu sebesar 10 persen, 38 sampai 47 tahun yaitu sebesar 8 persen dan 48 sampai 57 sebesar 5 persen. Berdasarkan pendidikan terakhir, mayoritas responden dengan tingkat pendidikan S1 sebesar 56 persen, yang diikuti oleh responden SMA sebesar 17 persen, kemudian responden dengan tingkat pendidikan Diploma sebesar 14 persen dan S2 sebesar 13 persen.

Penilaian variabel identifikasi merek diukur melalui persepsi responden terhadap tiga indikator yaitu sebagai berikut.

Tabel 1. Deskripsi Variabel Identifikasi Merek

\begin{tabular}{lccccccc}
\hline \multicolumn{1}{c}{ Indikator } & STS & TS & N & S & SS & $\begin{array}{c}\text { Rata-Rata } \\
\text { Skor }\end{array}$ & Keterangan \\
\hline $\begin{array}{l}\text { Saya ingat dengan simbol atau logo } \\
\text { iPhone }\end{array}$ & 1 & 8 & 31 & 27 & 33 & 3,83 & Baik \\
$\begin{array}{l}\text { Saya mampu membedakan iPhone } \\
\text { dengan merek lain }\end{array}$ & 0 & 11 & 28 & 33 & 28 & 3,78 & Baik \\
$\begin{array}{l}\text { Saya mengerti slogan iPhone sesuai } \\
\text { dengan maksud perusahaan Apple }\end{array}$ & 0 & 10 & 33 & 25 & 32 & 3,79 & Baik \\
\hline \multicolumn{1}{c}{ Rata-rata skor } & & & & & 3,80 & Baik \\
\hline
\end{tabular}

Sumber: Data primer, diolah. 
I Dewa Gede Kresna Wurawan, Putu Gde Sukaatmadja. Peran Kecintaan Merek...

Berdasarkan Tabel 1 skor rata-rata persepsi responden terhadap variabel identifikasi merek adalah sebesar 3,80, dengan demikian dapat dinyatakan bahwa variabel identifikasi merek yang dibentuk oleh tiga indikator dalam kategori baik.

Penilaian variabel kepercayaan merek diukur melalui presepsi responden terhadap tiga indikator yaitu sebagai berikut.

Tabel 2. Deskripsi Variabel Kepercayaan Merek

\begin{tabular}{|c|c|c|c|c|c|c|c|}
\hline Indikator & STS & TS & $\mathbf{N}$ & $\mathbf{S}$ & SS & $\begin{array}{l}\text { Rata-Rata } \\
\text { Skor }\end{array}$ & Keterangan \\
\hline Saya percaya terhadap iPhone & 0 & 6 & 27 & 28 & 39 & 4,00 & Baik \\
\hline $\begin{array}{l}\text { Menurut saya iPhone aman } \\
\text { digunakan }\end{array}$ & 0 & 7 & 28 & 33 & 32 & 3,90 & Sangat Baik \\
\hline $\begin{array}{l}\text { Kejujuran smartphone iPhone } \\
\text { sudah terbukti }\end{array}$ & 1 & 3 & 31 & 26 & 39 & 3,99 & Baik \\
\hline \multicolumn{6}{|c|}{ Rata-rata skor } & 3,96 & Baik \\
\hline
\end{tabular}

Sumber: Data primer, diolah.

Berdasarkan Tabel 2 skor rata-rata persepsi responden terhadap variabel kepercayaan merek adalah sebesar 3,96, dengan demikian dapat dinyatakan bahwa variabel identifikasi merek yang dibentuk oleh tiga indikator dalam kategori baik.

Penilaian variabel kecintaan merek diukur melalui presepsi responden terhadap lima indikator yaitu sebagai berikut.

Tabel 3. Deskripsi Variabel Kecintaan Merek

\begin{tabular}{|c|c|c|c|c|c|c|c|}
\hline Indikator & STS & TS & $\mathbf{N}$ & $\mathbf{S}$ & SS & $\begin{array}{c}\text { Rata-Rata } \\
\text { Skor }\end{array}$ & Keterangan \\
\hline $\begin{array}{l}\text { Saya mengenal iPhone adalah } \\
\text { merek yang bagus }\end{array}$ & 1 & 3 & 35 & 23 & 38 & 3,94 & Baik \\
\hline Saya butuh dengan iPhone & 3 & 14 & 18 & 32 & 33 & 3,78 & Baik \\
\hline $\begin{array}{l}\text { Penilaian saya positif terhadap } \\
\text { iPhone }\end{array}$ & 1 & 8 & 29 & 24 & 38 & 3,90 & Baik \\
\hline $\begin{array}{l}\text { Respon emosional saya positif } \\
\text { pada iPhone }\end{array}$ & 0 & 7 & 28 & 32 & 33 & 3,91 & Baik \\
\hline Saya cinta terhadap iPhone & 1 & 5 & 35 & 30 & 29 & 3,81 & Baik \\
\hline \multicolumn{6}{|c|}{ Rata-rata skor } & 3,87 & Baik \\
\hline
\end{tabular}

Sumber: Data primer, diolah. 
I Dewa Gede Kresna Wurawan, Putu Gde Sukaatmadja. Peran Kecintaan Merek...

Berdasarkan Tabel 5.4 skor rata-rata persepsi responden terhadap variabel kecintaan merek adalah sebesar 3,87, dengan demikian dapat dinyatakan bahwa variabel kecintaan merek yang dibentuk oleh lima indikator dalam kategori baik.

Penilaian variabel komitmen merek diukur melalui persepsi responden terhadap enam indikator yaitu sebagai berikut.

Tabel 4. Deskripsi Variabel Komitmen Merek

\begin{tabular}{|c|c|c|c|c|c|c|c|}
\hline Indikator & STS & TS & $\mathbf{N}$ & $\mathbf{S}$ & SS & $\begin{array}{l}\text { Rata-Rata } \\
\text { Skor }\end{array}$ & Keterangan \\
\hline $\begin{array}{l}\text { Secara emosional ada } \\
\text { keterikatan terhadap iPhone }\end{array}$ & 1 & 6 & 34 & 26 & 33 & 3,84 & Baik \\
\hline $\begin{array}{l}\text { Produk iPhone penting dalam } \\
\text { hidup saya }\end{array}$ & 2 & 20 & 24 & 29 & 25 & 3,55 & Baik \\
\hline Saya tertarik terhadap iPhone & 3 & 10 & 29 & 25 & 33 & 3,75 & Baik \\
\hline Saya puas terhadap iPhone & 1 & 13 & 22 & 37 & 27 & 3,76 & Baik \\
\hline $\begin{array}{l}\text { Produk iPhone lebih baik dari } \\
\text { merek lain }\end{array}$ & 1 & 8 & 32 & 21 & 38 & 3,87 & Baik \\
\hline Saya loyal terhadap iPhone & 0 & 12 & 30 & 20 & 38 & 3,84 & Baik \\
\hline \multicolumn{6}{|c|}{ Rata-rata skor } & 3,77 & Baik \\
\hline
\end{tabular}

Sumber: Data primer, diolah.

Berdasarkan Tabel 4 skor rata-rata persepsi responden terhadap variabel komitmen merek adalah sebesar 3,77, dengan demikian dapat dinyatakan bahwa variabel komitmen merek yang dibentuk oleh enam indikator dalam kategori baik.

Tabel 5. Deskripsi Variabel Word-of-mouth

\begin{tabular}{|c|c|c|c|c|c|c|c|}
\hline Indikator & STS & TS & $\mathbf{N}$ & $\mathbf{S}$ & SS & $\begin{array}{l}\text { Rata-Rata } \\
\text { Skor }\end{array}$ & Keterangan \\
\hline $\begin{array}{l}\text { Saya menganjurkan keluarga atau } \\
\text { teman untuk membeli iPhone }\end{array}$ & 5 & 7 & 30 & 26 & 32 & 3,73 & Baik \\
\hline $\begin{array}{l}\text { Saya kerap merekomendasikan } \\
\text { iPhone jika ada yang bertanya }\end{array}$ & 6 & 11 & 28 & 25 & 30 & 3,62 & Baik \\
\hline $\begin{array}{l}\text { Saya merekomendasikan smartphone } \\
\text { iPhone jika ada percakapan tentang } \\
\text { kategori merek Apple }\end{array}$ & 5 & 7 & 29 & 24 & 35 & 3,77 & Baik \\
\hline $\begin{array}{l}\text { Saya sudah merekomendasikan } \\
\text { iPhone ke keluarga atau teman }\end{array}$ & 6 & 9 & 30 & 27 & 28 & 3,62 & Baik \\
\hline \multicolumn{6}{|l|}{$\begin{array}{ll}\text { Rata-rata skor } \\
\end{array}$} & 3,69 & Baik \\
\hline
\end{tabular}

Sumber: Data primer, diolah.

Penilaian variabel word-of-mouth diukur melalui presepsi responden terhadap empat indikator yaitu: menganjurkan keluarga atau teman untuk membeli 
I Dewa Gede Kresna Wurawan, Putu Gde Sukaatmadja. Peran Kecintaan Merek...

produk, kerap merekomendasikan jika ada yang bertanya, merekomendasikan produk jika ada percakapan, dan sudah merekomendasikan produk ke keluarga atau teman, sebagai berikut. Berdasarkan Tabel 5 skor rata-rata persepsi responden terhadap variabel word-of-mouth adalah sebesar 3,69.

Penilaian kesediaan membayar dengan harga premium diukur melalui presepsi responden terhadap lima indikator yaitu sebagai berikut.

Tabel 6. Deskripsi Variabel Kesediaan Membayar Dengan Harga Premium

\begin{tabular}{|c|c|c|c|c|c|c|c|}
\hline Indikator & STS & TS & $\mathbf{N}$ & $\mathbf{S}$ & SS & $\begin{array}{c}\text { Rata-Rata } \\
\text { Skor }\end{array}$ & Keterangan \\
\hline $\begin{array}{l}\text { Saya bersedia membayar lebih } \\
\text { untuk iPhone yang mempunyai } \\
\text { kualitas yang unggul }\end{array}$ & 6 & 13 & 25 & 20 & 36 & 3,67 & Baik \\
\hline $\begin{array}{l}\text { Saya bersedia membayar dengan } \\
\text { harga premium untuk iPhone yang } \\
\text { saya pilih }\end{array}$ & 3 & 16 & 21 & 33 & 27 & 3,65 & Baik \\
\hline $\begin{array}{l}\text { Saya bersedia membayar lebih } \\
\text { untuk iPhone yang saya pilih } \\
\text { karena dapat membuat saya bangga }\end{array}$ & 5 & 8 & 30 & 20 & 37 & 3,76 & Baik \\
\hline $\begin{array}{l}\text { Saya bersedia membayar lebih } \\
\text { untuk iPhone yang mempunyai } \\
\text { standar mutu yang baik }\end{array}$ & 3 & 12 & 26 & 30 & 29 & 3,70 & Baik \\
\hline $\begin{array}{l}\text { Saya bersedia membayar lebih } \\
\text { untuk iPhone karena } \\
\text { menggambarkan kesuksesan saya }\end{array}$ & 5 & 12 & 25 & 24 & 34 & 3,70 & Baik \\
\hline \multicolumn{6}{|l|}{ Rata-rata skor } & 3,70 & Baik \\
\hline
\end{tabular}

Sumber: Data primer, diolah.

Berdasarkan Tabel 6, skor rata-rata persepsi responden terhadap variabel kesediaan membayar dengan harga premium adalah sebesar 3,70, dapat dinyatakan bahwa variabel kesediaan membayar dengan harga premium yang dibentuk oleh lima indikator dalam kategori baik.

Berikutnya data dianalisis menggunakan Partial Least Square (PLS). Terdapat dua evaluasi model dalam pengujian ini yaitu outer model dan inner model. Uji outer model ada tiga tahapan yaitu convergent validity, discriminant validity, dan composite reliability. 
Tabel 7. Uji Outer Model

\begin{tabular}{|c|c|c|c|c|c|}
\hline & Variabel dan Indikatornya & $\begin{array}{c}\text { Outer } \\
\text { Loading*) }\end{array}$ & AVE*) & $\begin{array}{c}\text { Composite } \\
\text { Reliability**) }\end{array}$ & $\begin{array}{l}\text { Cronbach } \\
\text { Alpha } * *)\end{array}$ \\
\hline \multicolumn{6}{|c|}{ Identifikasi Merek $\left(\mathbf{X}_{1}\right)$} \\
\hline$\left(\mathrm{X}_{1.1}\right)$ & Saya ingat dengan simbol iPhone & 0,911 & \multirow{3}{*}{0,828} & \multirow{3}{*}{0,935} & \multirow{3}{*}{0,896} \\
\hline$\left(\mathrm{X}_{1.2}\right)$ & $\begin{array}{l}\text { Saya mampu membedakan iPhone } \\
\text { dengan merek lain }\end{array}$ & 0,881 & & & \\
\hline$\left(\mathrm{X}_{1.3}\right)$ & $\begin{array}{l}\text { Saya mengerti slogan iPhone sesuai } \\
\text { dengan maksud perusahaan Apple }\end{array}$ & 0,938 & & & \\
\hline \multicolumn{6}{|c|}{ Kepercayaan Merek $\left(\mathbf{X}_{2}\right)$} \\
\hline$\left(\mathrm{X}_{2.1}\right)$ & Saya percaya terhadap iPhone & 0,910 & \multirow{3}{*}{0,833} & \multirow{3}{*}{0,937} & \multirow{3}{*}{0,900} \\
\hline$\left(\mathrm{X}_{2.2}\right)$ & Menurut saya iPhone aman digunakan & 0,883 & & & \\
\hline$\left(\mathrm{X}_{2.3}\right)$ & Kejujuran iPhone sudah terbukti & 0,944 & & & \\
\hline \multicolumn{6}{|c|}{ Kecintaan Merek $\left(\mathbf{Y}_{1}\right)$} \\
\hline$\left(\mathrm{Y}_{1.1}\right)$ & $\begin{array}{l}\text { Saya mengenal iPhone adalah merek } \\
\text { yang bagus }\end{array}$ & 0,836 & \multirow{5}{*}{0,748} & \multirow{5}{*}{0,937} & \multirow{5}{*}{0,916} \\
\hline$\left(\mathrm{Y}_{1.2}\right)$ & Saya butuh dengan iPhone & 0,878 & & & \\
\hline$\left(\mathrm{Y}_{1.3}\right)$ & Penilaian saya positif terhadap iPhone & 0,878 & & & \\
\hline$\left(\mathrm{Y}_{1.4}\right)$ & $\begin{array}{l}\text { Respon emosional saya positif pada } \\
\text { iPhone }\end{array}$ & & & & \\
\hline$\left(\mathrm{Y}_{1.5}\right)$ & Saya cinta terhadap iPhone & 0,848 & & & \\
\hline \multicolumn{6}{|c|}{ Komitmen Merek $\left(\mathbf{Y}_{2}\right)$} \\
\hline$\left(\mathrm{Y}_{2.1}\right)$ & $\begin{array}{l}\text { Secara emosional ada keterikatan } \\
\text { terhadap iPhone }\end{array}$ & 0,881 & \multirow{7}{*}{0,762} & \multirow{7}{*}{0,951} & \multirow{7}{*}{0,937} \\
\hline$\left(\mathrm{Y}_{2.2}\right)$ & Produk iPhone penting dalam hidup saya & 0,885 & & & \\
\hline$\left(\mathrm{Y}_{2.3}\right)$ & Saya tertarik terhadap iPhone & 0,863 & & & \\
\hline$\left(\mathrm{Y}_{2.4}\right)$ & Saya puas terhadap iPhone & 0,839 & & & \\
\hline$\left(\mathrm{Y}_{2.4}\right)$ & Saya puas terhadap iPhone & 0,839 & & & \\
\hline$\left(\mathrm{Y}_{2.5}\right)$ & $\begin{array}{l}\text { Produk iPhone lebih baik dari merek } \\
\text { lain }\end{array}$ & 0,910 & & & \\
\hline$\left(\mathrm{Y}_{2.6}\right)$ & Saya loyal terhadap iPhone & 0,858 & & & \\
\hline \multicolumn{6}{|c|}{ Word-of-mouth $\left(\mathbf{Y}_{3}\right)$} \\
\hline$\left(\mathrm{Y}_{3.1}\right)$ & $\begin{array}{l}\text { Saya menganjurkan keluarga atau } \\
\text { teman untuk membeli iPhone }\end{array}$ & 0,876 & \multirow{4}{*}{0,832} & \multirow{4}{*}{0,952} & \multirow{4}{*}{0,932} \\
\hline$\left(\mathrm{Y}_{3.2}\right)$ & $\begin{array}{l}\text { Saya kerap merekomendasikan iPhone } \\
\text { jika ada yang bertanya }\end{array}$ & 0,920 & & & \\
\hline$\left(\mathrm{Y}_{3.3}\right)$ & $\begin{array}{l}\text { Saya merekomendasikan iPhone jika } \\
\text { ada percakapan tentang kategori merek } \\
\text { Apple }\end{array}$ & 0,929 & & & \\
\hline$\left(\mathrm{Y}_{3.4}\right)$ & $\begin{array}{l}\text { Saya sudah merekomendasikan iPhone } \\
\text { ke keluarga atau teman }\end{array}$ & 0,921 & & & \\
\hline \multicolumn{6}{|c|}{ Kesediaan Membayar dengan Harga Premium $\left(\mathbf{Y}_{4}\right)$} \\
\hline$\left(\mathrm{Y}_{4.1}\right)$ & $\begin{array}{l}\text { Saya bersedia membayar lebih untuk } \\
\text { iPhone yang mempunyai kualitas yang } \\
\text { unggul }\end{array}$ & 0,914 & \multirow{4}{*}{0,836} & \multirow{4}{*}{0,962} & \multirow{4}{*}{0,951} \\
\hline$\left(\mathrm{Y}_{4.2}\right)$ & $\begin{array}{l}\text { Saya bersedia membayar dengan } \\
\text { harga premium untuk iPhone yang } \\
\text { saya pilih }\end{array}$ & 0,902 & & & \\
\hline$\left(\mathrm{Y}_{4.3}\right)$ & $\begin{array}{l}\text { Saya bersedia membayar lebih untuk } \\
\text { iPhone yang saya pilih karena dapat } \\
\text { membuat saya bangga }\end{array}$ & 0,933 & & & \\
\hline$\left(\mathrm{Y}_{4.4}\right)$ & $\begin{array}{l}\text { Saya bersedia membayar lebih untuk } \\
\text { iPhone yang mempunyai standar mutu }\end{array}$ & 0,895 & & & \\
\hline
\end{tabular}


I Dewa Gede Kresna Wurawan, Putu Gde Sukaatmadja. Peran Kecintaan Merek...

\begin{tabular}{lll} 
yang baik \\
\hline \multirow{4}{*}{$\begin{array}{l}\text { Saya bersedia membayar lebih untuk } \\
\text { iPhone karena menggambarkan } \\
\text { kesuksesan saya }\end{array}$} \\
\hline
\end{tabular}

Catatan: *) indikator valid apabila outer loadings dan AVE > 0,50

**) indikator reliabel apabila composite reliability dan cronbach alpha $>0,70$

Sumber: Data primer, diolah.

Berdasarkan Tabel 8 , nilai $R$-square pada kecintaan merek sebesar 0,786 yang dapat diinterpretasikan bahwa variabilitas variabel komitmen merek dapat dijelaskan oleh variabilitas variabel identifikasi dan kepercayaan merek sebesar 78,6 persen, sedangkan 22,4 persen sisanya dijelaskan oleh variabel lain diluar dari yang diteliti. Selanjutnya, nilai $R$-square pada komitmen merek sebesar 0,790 yang dapat diinterpretasikan bahwa variabilitas variabel komitmen merek dapat dijelaskan oleh variabilitas variabel identifikasi, kepercayaan, dan kecintaan merek sebesar 79 persen, sedangkan 21 persen sisanya dijelaskan oleh variabel lain diluar dari yang diteliti. Nilai $R$-square pada word-of-mouth sebesar 0,737 yang dapat diinterpretasikan bahwa variabilitas variabel komitmen merek dapat dijelaskan oleh variabilitas variabel kecintaan dan komitmen merek sebesar 73,7 persen, sedangkan 26,3 persen sisanya dijelaskan oleh variabel lain diluar dari yang diteliti. Nilai $R$-square pada word-of-mouth sebesar 0,630 yang dapat diinterpretasikan bahwa variabilitas variabel komitmen merek dapat dijelaskan oleh variabilitas variabel kecintaan dan komitmen merek sebesar 63 persen, sedangkan 37 persen sisanya dijelaskan oleh variabel lain diluar dari yang diteliti. 
Tabel 8. R-Square

\begin{tabular}{lc}
\hline \multicolumn{1}{c}{ Variabel } & R-square \\
\hline Kecintaan merek & 0,786 \\
Komitmen merek & 0,790 \\
Word-of-mouth & 0,737 \\
Kesediaan membayar dengan harga premium & 0,630 \\
\hline
\end{tabular}

Sumber: Hasil penelitian, 2017

Untuk mengukur seberapa baik nilai observasi dihasilkan oleh model dan juga estimasi parameternya, maka perlu menghitung $Q$-square (Q2) sebagai berikut:

$$
\begin{aligned}
\mathrm{Q} 2= & 1-(1-(\mathrm{R} 1) 2)(1-(\mathrm{R} 2) 2) \\
& (1-(\mathrm{R} 2) 2)(1-(\mathrm{R} 2) 2) \\
= & 1-(1-0,786)(1-0,790) \\
& (1-0,737)(1-0,630) \\
= & 0,996
\end{aligned}
$$

Hasil tersebut menunjukkan nilai predictive - relevance sebesar 0,996, nilai ini > 0. Sehingga dapat diartikan bahwa 99,6 persen variasi pada variabel intense keluar dijelaskan oleh variabel yang digunakan pada model. Sisanya sebesar 0,4 persen dijelaskan oleh faktor lainnya diluar model. Dengan hasil ini maka dijelaskan model ini memiliki nilai prediksi yang relevan. 
Tabel 9. Path Coefficients

\begin{tabular}{lccc}
\hline \multicolumn{1}{c}{ Konstruk } & Koefisien Korelasi & t Statistics & Keterangan \\
\hline Identifikasi merek -> Kecintaan merek & 0,474 & 4,558 & Signifikan \\
Identifikasi merek -> Komitmen merek & 0,589 & 5,929 & Signifikan \\
Kepercayaan merek -> Kecintaan merek & 0,466 & 4,382 & Signifikan \\
Kepercayaan merek -> Komitmen merek & 0,336 & 3,200 & Signifikan \\
Kecintaan merek -> Komitmen merek & 0,318 & 2,982 & Signifikan \\
Kecintaan merek -> Word-of-mouth & 0,670 & 7,337 & Signifikan \\
$\begin{array}{l}\text { Komitmen merek -> Word-of-mouth } \\
\text { Kecintaan merek -> Kesediaan }\end{array}$ & 0,326 & 2,452 & Signifikan \\
$\begin{array}{l}\text { membayar dengan harga premium } \\
\text { Komitmen merek -> Kesediaan }\end{array}$ & 0,546 & \multirow{2}{*}{0,582} & Signifikan \\
membayar dengan harga premium & & \multirow{2}{*}{2,919} & \multirow{2}{*}{ Signifikan } \\
\hline
\end{tabular}

Sumber: Data primer, diolah.

\section{Pengaruh Identifikasi Merek Terhadap Kecintaan Merek}

Pada Tabel 9, pengujian pengaruh identifikasi merek terhadap kecintaan merek dijelaskan pada Tabel 5.14 yang menunjukkan bahwa identifikasi merek memiliki pengaruh positif dan signifikan terhadap kecintaan merek. Hal ini ditunjukkan dari nilai koefisien jalur (path) dari identifikasi merek ke kecintaan merek sebesar 0,474 dan nilai t-statistik sebesar 4,558 (> t-tabel). Hal ini memiliki makna bahwa peningkatan identifikasi merek dapat meningkatkan kecintaan merek pengguna smartphone iPhone dengan baik. Temuan penelitian ini mendukung penelitian Albert and Merunka (2013) dan Motahari et al. (2014), dimana menunjukkan hasil bahwa identifikasi merek berpengaruh positif terhadap kecintaan merek.

\section{Pengaruh Identifikasi Merek Terhadap Komitmen Merek}

Tabel 9 menunjukkan bahwa identifikasi merek memiliki pengaruh positif dan signifikan terhadap komitmen merek. Hal ini ditunjukkan dari nilai koefisien jalur (path) dari identifikasi merek ke komitmen merek sebesar 0,589 dan nilai tstatistik sebesar 5,929 (> t - tabel 1,96). Hal ini memiliki makna bahwa semakin 
I Dewa Gede Kresna Wurawan, Putu Gde Sukaatmadja. Peran Kecintaan Merek...

kuat identifikasi merek maka dapat meningkatkan komitmen merek pengguna smartphone iPhone. Hasil ini mendukung dengan penelitian-penelitian sebelumnya seperti Albert and Merunka (2013), Kazemi et al. (2013), Bachman and Wilkins (2014) yang menunjukkan identifikasi merek berpengaruh positif terhadap komitmen merek.

\section{Pengaruh Kepercayaan Merek Terhadap Kecintaan Merek}

Pengujian pengaruh kepercayaan merek terhadap kecintaan merek dijelaskan pada Tabel 9 yang menunjukkan bahwa kepercayaan merek memiliki pengaruh positif dan signifikan terhadap kecintaan merek. Hal ini ditunjukkan dari nilai koefisien jalur (path) dari identifikasi merek ke komitmen merek sebesar 0,466 dan nilai t-statistik sebesar 4,382 (>t - tabel 1,96). Hal ini memiliki makna bahwa peningkatan kepercayaan merek dapat meningkatkan kecintaan merek pengguna smartphone iPhone. Hasil penelitian ini mendukung temuan Albert and Merunka (2013), Koschate and Gartner (2013), dan Susanti (2015), yang menyatakan bahwa kepercayaan merek berpengaruh signifikan terhadap kecintaan merek pada pengguna sepatu Adidas di Surabaya.

\section{Pengaruh Kepercayaan Merek Terhadap Komitmen Merek}

Pengujian pengaruh kepercayaan merek terhadap komitmen merek dijelaskan pada Tabel 9 yang menunjukkan bahwa kepercayaan merek memiliki pengaruh positif dan signifikan terhadap komitmen merek. Hal ini ditunjukkan dari nilai koefisien jalur (path) dari kepercayaan merek ke komitmen merek 
I Dewa Gede Kresna Wurawan, Putu Gde Sukaatmadja. Peran Kecintaan Merek...

sebesar 0,336 dan nilai t-statistik sebesar 3,200 (>t - tabel 1,96). Hal ini memiliki makna bahwa semakin kuat kepercayaan merek maka komitmen pengguna terhadap smartphone merek iPhone semakin meningkat. Hasil penelitian ini mendukung temuan Louis and Lombart (2010), Li et al. (2014), dan Susanti (2015) bahwa kepercayaan merek berpengaruh positif signifikan terhadap komitmen merek.

\section{Pengaruh Kecintaan Merek Terhadap Komitmen Merek}

Pengujian pengaruh kecintaan merek terhadap komitmen merek dijelaskan pada Tabel 9 yang menunjukkan bahwa kecintaan merek memiliki pengaruh positif dan signifikan terhadap komitmen merek. Hal ini ditunjukkan dari nilai koefisien jalur (path) dari kecintaan merek ke komitmen merek sebesar 0,318 dan nilai t-statistik sebesar 2,982 (> t - tabel 1,96). Hal ini memiliki makna bahwa dengan meningkatnya kecintaan merek dapat meningkatkan komitmen merek pengguna smartphone iPhone. Hasil ini sesuai dengan penelitian Ike and Tan (2009), Albert and Merunka (2013), dan Susanti (2015) menunjukkan kecintaan merek berpengaruh terhadap komitmen merek.

\section{Pengaruh Kecintaan Merek Terhadap Word-of-mouth}

Pengujian pengaruh kecintaan merek terhadap word-of-mouth dijelaskan pada Tabel 9 yang menunjukkan bahwa kecintaan merek memiliki pengaruh positif dan signifikan terhadap word-of-mouth. Hal ini ditunjukkan dari nilai koefisien jalur (path) dari kecintaan merek ke word-of-mouth sebesar 0,670 dan nilai t-statistik sebesar 7,337 (> t - tabel 1,96). Hal ini memiliki makna bahwa 
I Dewa Gede Kresna Wurawan, Putu Gde Sukaatmadja. Peran Kecintaan Merek...

naiknya kecintaan merek mampu meningkatkan perilaku word-of-mouth pengguna smartphone iPhone. Hasil ini sejalan dengan penelitian Ismail et al. (2012), Albert and Merunka (2013), dan Ahdah (2014) yang menunjukkan bahwa kecintaan merek berpengaruh terhadap word-of-mouth.

\section{Pengaruh Komitmen Merek Terhadap Word-of-mouth}

Pengujian pengaruh komitmen merek terhadap word-of-mouth dijelaskan pada Tabel 9 yang menunjukkan bahwa komitmen merek memiliki pengaruh positif dan signifikan terhadap word-of-mouth. Hal ini ditunjukkan dari nilai koefisien jalur (path) dari komitmen merek ke word-of-mouth sebesar 0,326 dan nilai t-statistik sebesar 2,452 (> t - tabel 1,96). Hal ini memiliki makna bahwa peningkatan komitmen merek dapat meningkatkan word-of-mouth pengguna smartphone iPhone. Hasil ini sesuai dengan penelitian Albert and Merunka (2013), Tuskej et al. (2013), Maisam and Mahsa (2016) yang menunjukkan komitmen merek berpengaruh positif yang signifikan terhadap word-of-mouth

\section{Pengaruh Kecintaan Merek Terhadap Kesediaan Membayar dengan Harga Premium}

Pengujian pengaruh kecintaan merek terhadap kesediaan membayar dengan harga premium dijelaskan pada Tabel 9 yang menunjukkan bahwa kecintaan merek memiliki pengaruh positif dan signifikan terhadap kesediaan membayar dengan harga premium. Hal ini ditunjukkan dari nilai koefisien jalur 
I Dewa Gede Kresna Wurawan, Putu Gde Sukaatmadja. Peran Kecintaan Merek...

(path) dari kecintaan merek ke kesediaan membayar dengan harga premium sebesar 0,546 dan nilai t-statistik sebesar 4,582 (> t - tabel 1,96). Hal ini memiliki makna bahwa peningkatan kecintaan merek mampu meningkatkan kesediaan membayar dengan harga premium pengguna smartphone iPhone dengan baik. Hasil ini sesuai dengan studi Rodrigues and Reis (2013), Albert and Merunka (2013), dan Cantista (2015) yang menunjukkan kecintaan merek berpengaruh positif yang signifikan terhadap kesediaan membayar dengan harga premium.

\section{Pengaruh Komitmen Merek Terhadap Kesediaan Membayar dengan Harga}

\section{Premium}

Pengujian pengaruh komitmen merek terhadap kesediaan membayar dengan harga premium dijelaskan pada Tabel 9 yang menunjukkan bahwa komitmen merek memiliki pengaruh positif signifikan terhadap kesediaan membayar dengan harga premium. Hal ini ditunjukkan dari nilai koefisien jalur (path) dari komitmen merek ke kesediaan membayar dengan harga premium sebesar 0,412 dan nilai t-statistik sebesar 2,919 (> t - tabel 1,96). Hal ini memiliki makna bahwa peningkatan komitmen merek dapat meningkatkan kesediaan membayar dengan harga premium pengguna iPhone. Hasil ini sesuai dengan penelitian Chaudhuri and Holbrook (2002) dan Albert and Merunka (2013) yang menemukan komitmen merek berpengaruh positif dan signifikan terhadap kesediaan membayar dengan harga premium.

Berdasarkan hasil penelitian, identifikasi merek memiliki pengaruh yang paling besar terhadap kecintaan merek dan komitmen merek. Pengguna cenderung mengingat keunikan dari logo Apple yang disematkan pada iPhone. Penting bagi 
I Dewa Gede Kresna Wurawan, Putu Gde Sukaatmadja. Peran Kecintaan Merek...

pihak manajemen untuk meningkatkan kesadaran merek iPhone sehingga pengguna dapat dengan mudah mengenali merek melalui bentuk produk, durabilitas produk, dan kecanggihannya. Hal ini tentunya akan mendorong identifikasi merek selain dari logo merek. Ini tentunya akan berdampak pada penilaian positif terhadap iPhone dan meningkatkan emosional pengguna sehingga pengguna memandang iPhone merupakan merek yang terbaik. Inilah yang menjadi cerminan bahwa pengguna menjadi loyal terhadap iPhone.

\section{SIMPULAN DAN SARAN}

Berdasarkan hasil pembahasan, maka dapat disimpulkan bahwa, identifikasi merek dan kepercayaan merek memiliki pengaruh positif dan signifikan terhadap kecintaan merek. Hal ini memiliki makna bahwa peningkatan identifikasi merek dan kepercayaan merek dapat meningkatkan kecintaan merek pengguna iPhone. Identifikasi merek dan kepercayaan merek memiliki pengaruh positif dan signifikan terhadap komitmen merek. Hal ini memiliki makna bahwa peningkatan identifikasi merek dan kepercayaan merek dapat meningkatkan komitmen merek pengguna iPhone.

Kecintaan merek memiliki pengaruh positif dan signifikan terhadap komitmen merek, word-of-mouth, dan kesediaan untuk membayar dengan harga premium. Hal ini memiliki makna bahwa semakin tinggi kecintaan merek, maka semakin tinggi pula komitmen merek, komunikasi word-of-mouth, dan kesediaan pengguna iPhone untuk membayar dengan harga premium. Komitmen merek memiliki pengaruh positif dan signifikan terhadap word-of-mouth dan kesediaan 
untuk membayar dengan harga premium. Hal ini memiliki makna bahwa semakin tinggi komitmen merek, maka semakin tinggi pula komunikasi word-of-mouth dan kesediaan pengguna iPhone untuk membayar dengan harga premium.

Berdasarkan hasil penelitian dan simpulan, beberapa saran untuk meningkatkan kepercayaan merek dan komitmen merek yang masih kurang.

1) Untuk meningkatkan kepercayaan merek, perusahaan perlu meningkatkan keamanan produk iPhone dengan menambah fitur-fitur yang lebih canggih. Hal ini dapat dikarenakan isu dari pengalaman pengguna iPhone yang merasa bahwa akun dan data-data pribadinya mampu diretas oleh orang lain.

2) Dalam hal komitmen merek, perusahaan perlu menekankan kepada pengguna bahwa iPhone merupakan hal yang penting di jaman seperti ini. Hanya dengan iPhone pengguna dapat berkomunikasi dan bersenang-senang dengan nyaman karena memiliki teknologi canggih dan kualitas produk yang tahan lama, sehingga pengguna tidak perlu lagi mencari merek lain.

3) Penelitian selanjutnya diharapkan menambahkan variabel terkait yang belum digunakan penelitian ini. Variabel dimaksud dapat berupa citra merek, ekuitas merek dan intensi pembelian.

4) Penelitian ini menggunakan metode PLS-SEM, penelitian selanjutnya diharapkan menggunakan analisis Path agar dapat menguji besarnya sumbangan (kontribusi) yang ditunjukkan oleh koefisien jalur pada setiap diagram jalur dari hubungan kausal antar variabel.

\section{REFERENSI}


I Dewa Gede Kresna Wurawan, Putu Gde Sukaatmadja. Peran Kecintaan Merek...

Aaker, D. 2015. Aaker On Branding: 20 Prinsip Esensial Mengelola dan Mengembangkan Brand. Jakarta: PT. Gramedia Pustaka Utama.

Ahdah, R. 2014. Pengaruh Identitas Merek, Komitmen Merek, Kecintaan Merekdan Citra Merek Terhadap Komunikasi Mulut Ke Mulut Produk Perawatan Kulit Natasha Skin Care di Surabaya. Artikel Ilmiah, 30(3), 2344.

Albert, N., and Merunka, D. 2013. The Role of Brand Love in Consumer-Brand Relationships. Journal of Consumer Marketing, 30,(3), 258-266.

Bachman, K. and Wilkins, S. 2014. Brand Commitment and Consumer-Brand Identification as Determinants of Consumers'Brand Loyalty and Repurchase Intentions, Third Edition. Northwestern: Evanston IL.

Bhattacharya, C. B., Sankar, S and Daniel, K. 2011. Leveraging Corporate Responsibility: The Stakeholder Route to Maximizing Business and Social Value. Cambridge: Cambridge University Press.

Cantista, I. 2015. Consumer Behavior: How the "Brand Love" Affects You. Marketing Science: Proceedings of Academy of Marketing Science, 2(9), 354-401.

Chaudhuri, A. and Holbrook, M. B. 2001. The Chain Effects of Brand Trust and Brand Affect to Brand Performance: The Role of Brand Loyalty. Journal of Marketing, 65(2), 81-93.

Fatih, G and Hayrettin, Z. 2013. The Relationship between Brand Trust, Brand Affect, Attitudinal Loyalty and Behavioral Loyalty: A Field Study towards Sports Shoe Consumers in Turkey. International Journal of Marketing Studies, 5(2), 111-119.

Ferrinadewi, E. 2008. Merek \& Psikologi Konsumen. Yogyakarta: Graha Ilmu.

Ghozali, I. 2011. Structural Equation Modelling Metode Alternatif dengan Partial Least Square (PLS) Edisi 3. Semarang: Badan Penerbit Universitas Diponegoro.

Ike, E, Ogba and Tan, Z. 2009. Exploring the Impact of Brand Image on Customer Loyalty and Commitment in China. Newcastle: Northumbria University.

Ismail, R., Ahmed and Spinelli, G. 2012. Effects of Brand Love, Personality and Image on Word of Mouth. Journal of Fashion Marketing and Management, 16(4), 386-398.

Jing, Z., Pitsaphol, C., and Shabbir, R. 2014. The Influence of Brand Awareness, Brand Image and Perceived Quality on Brand Loyalty: A Case Study of Oppo Brand In Thailand. Interdisciplinary Journal of Contemporary Research in Business, 5(2), 10-21. 
I Dewa Gede Kresna Wurawan, Putu Gde Sukaatmadja. Peran Kecintaan Merek...

Kartajaya, H. 2006. Hermawan Kartajaya on Service. Bandung: Mizan.

Kazemi, A, Vahid, M, Arash, A and Javad, P. 2013. Impact of Brand Identity on Customer Loyality and Word of Mouth Communications, Considering Mediating Role of Customer Satisfaction and Brand Commitment. Journal of Academic Research in Economics and Management Sciences, 2(4), 114.

Koschate, F, Nicole and Gartner, S. 2013. Brand Trust: Scale Development and Validation. Journal of Management Sciences, 6(12), 10-68.

Kotler, P and Keller, L. 2016. Marketing Management. 14 Edition. United States of America: Person.

Li, N., Robson, A., and Coates, N. 2014. Luxury brand commitment: A study of Chinese consumers, Marketing Intelligence and Planning, 32(7), 769-793.

Louis, D and Lombart, C. 2010. Impact of Brand Personality on Three Major Relational Consequences. Journal of Product \& Brand Management, 19(2), 114-130.

Maisam, S. and Mahsa, R. 2016. Positive Word of Mouth Marketing: Explaining the Roles of Value Congruity and Brand Love. Journal of Competitiveness, 8(1), 19-37.

Motahari, N. F., Samadi, S., Tolabi, Z., and Allah, A. Y. 2014. Investigation of Brand-Consumer Relationship: Study Item: Electrical Appliances. Market management magazine, 23(2), 24-38.

Netemeyer, R. G., Krishnan, B., Pullig, C., Wang, G., Yagci, M. dan Dean, D. 2004. Developing and Validating Measures of Facets of Customer-Based Brand Equity. Journal of Business Research, 57(2), 209-224.

O'Cass, A. and Mcewen, H. 2004. Exploring Consumer Status and Conspicuous Consumption. Journal of Consumer Behaviour, 4(1), 25-39.

Rodrigues, P and Reis, R. 2013. The Influence of "Brand Love" In Consumer Behavior-The Case of Zara and Modalfa Brands. Proceedings of 22nd International Business Research Conference, 8(1), 69-98.

Sallam, M.A. 2014. The Effect of Brand Image and Brand Identification on Brand Love and Purchace Making: The Role of WOM. Published by Canadian Center of Science and Education, 2(9), 10-78.

Sekaran, U. 2011. Research Methods for business, Edisi I and 2. Jakarta: Salemba Empat.

Sumardy, M.S, dan Melina, M. 2011. The Power of Word of Mouth, Edisi pertama. Jakarta: Andi. 
I Dewa Gede Kresna Wurawan, Putu Gde Sukaatmadja. Peran Kecintaan Merek...

Susanti, Y.H. 2015. Pengaruh Kepercayaan Merek, Kecintaan Merek dan Komitmen Merek terhadap Word of Mouth pada Pengguna Sepatu Adidas di Surabaya. Jurnal Pemasaran, 21(3), 10-45.

Tuskej, U., Golob, U., and Podnar, K. 2013. The Role of Consumer-Brand Identification in Building Brand Relationships. Journal of Business Research, 66(1), 53-59.

Walsh, M. F., Page, W, K. and Mittal, V. 2010. Do Logo Redesigns Help or Hurt Your Brand? The Role of Brand Commitment. Journal of Product \& Brand

Management, $19(2)$ $76-8$. 